\title{
Ectopic ureter in an adolescent female with vaginal discharge:
}

\section{a case report}

\author{
Avery M. Whitis BS, ${ }^{1}$ Colleen K. Stockdale MD, $\mathrm{MS}^{2}$
}

Key words: Ectopic ureter, vaginal discharge, urinary incontinence

\begin{abstract}
Background: An ectopic ureter inserts at a site other than the bladder neck, including urethra, vagina, and vestibule in women. These are typically diagnosed in childhood with the onset of continuous urinary incontinence after toilet training. However, they can be difficult to diagnose and rarely present in adults as urinary incontinence refractory to treatment.
\end{abstract}

Case: A 17-year-old female presented with a five-year history of profuse, watery vaginal discharge and recurrent urinary tract infections, in the setting of normal voiding patterns. Discharge was initially categorized as physiologic. After months without improvement, CT urogram revealed a duplex left sided ureteral system that drained the upper moiety of the left kidney and inserted into the vagina. She was treated with surgical ureteral reimplantation.

Conclusion: Ectopic ureters can commonly implant in the vagina and can rarely present with profuse, watery vaginal discharge in the setting of normal voiding patterns. Physicians must have a high index of suspicion for ectopic ureters in the patient with vaginal discharge refractory to treatment.
${ }^{1}$ University of lowa Carver College of Medicine, lowa City, lowa

${ }^{2}$ University of lowa Hospitals and Clinics, Department of Obstetrics and Gynecology, lowa City, lowa

\section{Introduction}

Ureteral ectopia is defined as a ureter that inserts at or distal to the bladder neck. ${ }^{1}$ There are many varieties of ectopic ureters, most of which are more common in females. ${ }^{1}$ They can be duplicated or single systems draining a duplex kidney, or single system draining an ectopic kidney. ${ }^{1}$ Greater than $80 \%$ drain the upper portion of a duplex kidney, while the other types are less common. ${ }^{1}$ They are thought to be due to abnormal ureteric bud origins from the mesonephric duct during embryological development. $^{2}$ Common sites of ectopic ureteral implantation in females include the urethra (35\%), vestibule (35\%), and vagina $(35 \%)^{1}$

Please cite this paper as: Whitis AM, Stockdale CK. Ectopic ureter in an adolescent female with vaginal discharge: a case report. Proc Obstet Gynecol. 2016;6(3): Article 6 [ 4 p.]. Available from: http://ir.uiowa.edu/pog/ Free full text article.

Corresponding author: Colleen Stockdale, MD, MS, Department of Obstetrics and Gynecology, 200 Hawkins Drive, Iowa City, IA 52246, Phone: 319-384-6849, Fax: 319-384-8620. Email: colleen-stockdale@uiowa.edu

Financial Disclosure: The authors report no conflict of interest.

Copyright: (c) 2016 Whitis et al. This is an open-access article distributed under the terms of the Creative Commons Attribution License, which permits unrestricted use, distribution, and reproduction in any medium, provided the original author and source are credited. 
These unusual pathologies in females typically present in childhood with continuous dribbling of urine after successful toilet training or frequent urinary tract infections. ${ }^{1,3}$ The incontinence is usually superimposed on a normal voiding pattern and can cause a raw and erythematous perineal rash. ${ }^{1,4}$ Antenatal diagnosis is also becoming increasingly more common with the detection of hydronephrosis in utero. ${ }^{3}$ Ureteral ectopia is historically difficult to diagnose due to the large differential diagnosis associated with urinary incontinence (detrusor inactivity, bladder obstruction, neurologic disorders, urogenital fistula, urethral diverticula, etc.), and are especially difficult to find if they are draining a hypofunctioning kidney due to lack of positive imaging findings. ${ }^{5}$ Because of this, diagnoses are at times unfortunately made later in life, with case reports of women being diagnosed as late as 70 years of age. ${ }^{1}$ Studies have shown a mean delay in definitive diagnosis as anywhere from 2 to 5 years after initial presentation. ${ }^{1,5}$ This indicates that there must be a high index of suspicion for ectopic ureter in a girl or woman presenting with unrelenting urinary incontinence regardless of age. . $^{1,3,4,5}$

This case details a 17-year-old adolescent female with an ectopic ureter diagnosed late in life. Her chief complaint, however, was not of urinary incontinence, but of vaginal discharge.

\section{Case}

A 17-year-old G0 female presented to the vulvar vaginal disease clinic for evaluation of profuse vaginal discharge for the past 5 years. The discharge was described as watery, nonbloody, nonodorous, non-purulent, and progressively increasing in amount. She wore daily maxi pads to absorb the discharge. She also had experienced 5 urinary tract infections in the past year treated with antibiotics and vulvar irritation treated with A\&D ointment. Neither of these interventions provided any relief in symptoms. She described her voiding as normal with no leakage and moderate volume. History was negative for urinary tract procedures. Exam was significant for erythema of the labia majora extending to the vestibule circumferentially, cervical ectropion, and a moderate amount of clear discharge in the posterior vaginal vault that was negative on wet prep. Due to the discharge not starting until age 12 , description of normal voiding function, and negative history of genitourinary procedures, ectopic ureter and vesicovaginal fistula were low on the differential. The discharge was initially categorized as physiologic and she was treated for contact dermatitis with Mycolog ointment in addition to discontinuation of contact irritants.

On return the patient reported persistent symptoms including 2 more urinary tract infections. Her exam was unchanged. Further evaluation included a transvaginal ultrasound that was negative for pelvic pathology and a negative methylene blue - tampon dye test; in which a vaginal tampon was negative for blue dye following instillation of methylene blue into the bladder for 7 minutes. The patient also switched from combined to progestin only contraceptives in an attempt to lessen the discharge, and considered cryotherapy to determine if the 
discharge was related to cervical ectropion.

Given persistent symptoms the patient underwent a CT urogram, which demonstrated a duplex left ureteral system and ectopic vaginal implantation of the left upper ureter (Figures 1, 2). A voiding cystourethrogram was negative for reflux or obstruction, and she was treated with a left open ureteral reimplantation with complete resolution of symptoms.

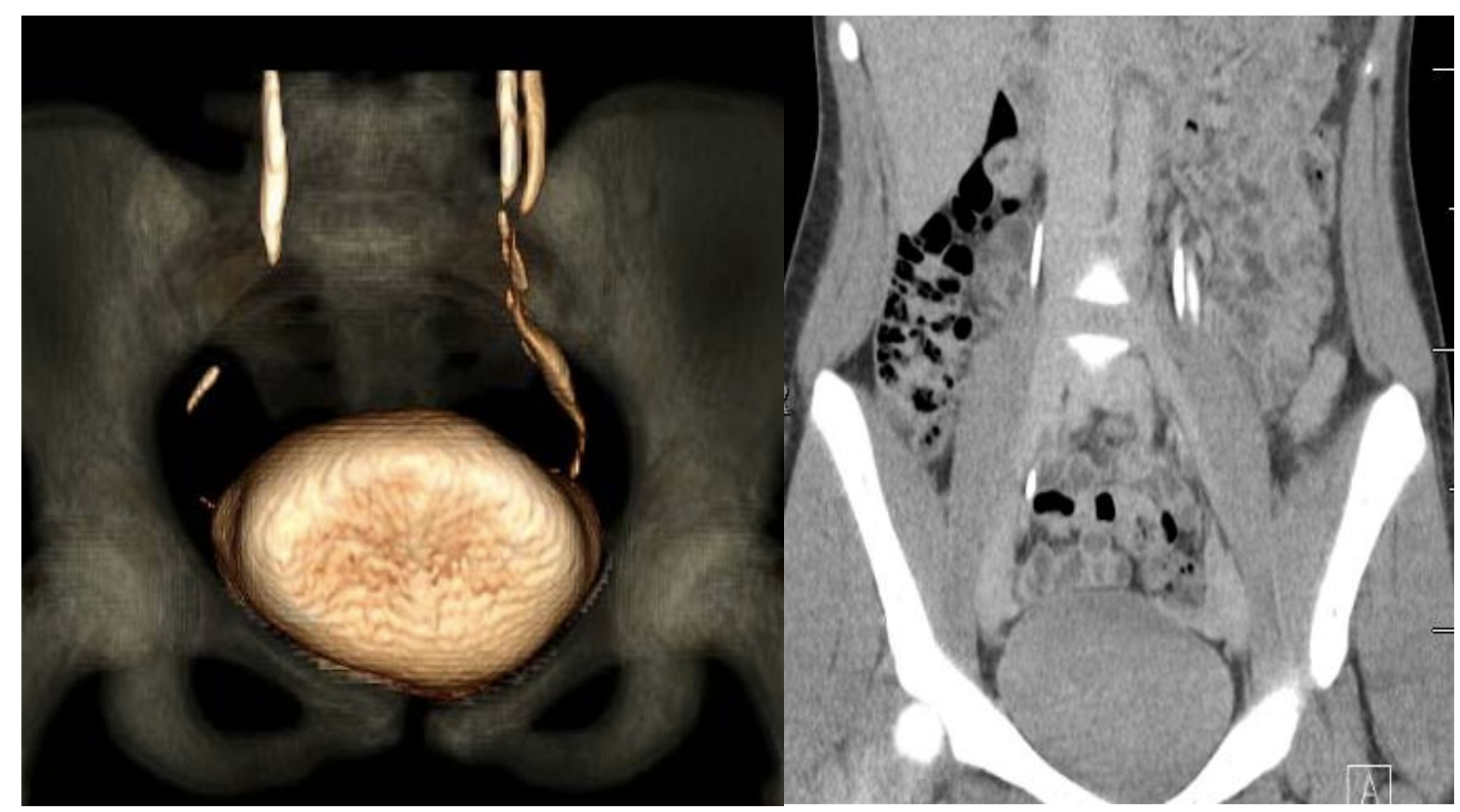

\section{Figures 1 and 2: CT Urogram demonstrating left sided duplex ureteral system}

\section{Discussion}

This case report details an atypical presentation of ectopic ureter. While this traditionally presents as a pediatric finding with urinary incontinence, this adolescent patient presented with vaginal discharge and normal voiding pattern, which lowered suspicion for ectopic ureter. The differential diagnosis for vaginal discharge is vast and includes physiologic changes throughout the menstrual cycle, hormonal changes of puberty, pregnancy, or menopause, cervical erosions, fistulae, and infectious diseases (candida, trichomonas, Gardnerella, Neisseria gonorrhea, chlamydia, herpes simplex virus). ${ }^{6}$

Other abnormal presentations of ectopic ureter have been detailed in case reports. Jain et al. detailed a patient with a history of back pain and frequent urinary tract infections due to a stenotic ureteric orifice in the vagina. ${ }^{7}$ Chai et al. summarized a case of ectopic ureter presenting with anterior vaginal wall prolapse. $^{8}$ Ectopic ureters can also present in adulthood after prolonged 
labor or genitourinary procedures due to creation of a fistula between the ectopic ureter and vagina. ${ }^{4}$

Diagnosis in our case was made by CT urogram, which is one of the most sensitive tests for ectopic ureter. ${ }^{5}$ Other diagnostic tests could include intravenous pyelogram, cystoscopy, and renal ultrasound. ${ }^{9}$ Treatment options are mainly surgical (ureteral reimplantation) and may include removal of a nonfunctional kidney or upper pole if indicated. $^{3}$

This case exemplifies the importance of keeping ectopic ureter in the differential diagnosis in cases of watery vaginal discharge.

\section{References}

1. Borer JG, Bauer SB, Peters CA, Diamond DA, Decter RM, Shapiro E. A single-system ectopic ureter draining an ectopic dysplastic kidney: delayed diagnosis in the young female with continuous urinary incontinence. $\mathrm{Br} \mathrm{J}$ Urol. $1998 \quad$ Mar;81(3):474-8. http://dx.doi.org/10.1046/j.1464410x.1998.00546.x PubMed PMID: 9523673

2. Roy Choudhury S, Chadha R, Bagga D, Puri A, Debnath PR. Spectrum of ectopic ureters in children. Pediatr Surg Int. $2008 \quad$ Jul;24(7):819-23. http://dx.doi.org/10.1007/s00383-0082172-2 Epub 2008 May 8. PubMed PMID: 18463883.

3. Albers P, Foster RS, Bihrle R, Adams MC, Keating MA. Ectopic ureters and ureteroceles in adults. Urology. 1995 May;45(5):870-4. http://dx.doi.org/10.1016/S00904295(99)80098-3 PubMed PMID: 7747379 .
4. Blacklock AR, Shaw RE, Geddes JR. Late presentation of ectopic ureter. $\mathrm{Br} \mathrm{J}$ Urol. $1982 \quad$ Apr;54(2):106-10. http://dx.doi.org/10.1111/j.1464410X.1982.tb13529.x PubMed PMID: 7200821.

5. Carrico C, Lebowitz RL. Incontinence due to an infrasphincteric ectopic ureter: why the delay in diagnosis and what the radiologist can do about it. Pediatr Radiol. $1998 \quad$ Dec;28(12):942-9. http://dx.doi.org/10.1007/s00247005050 6 PubMed PMID: 9880638.

6. Watson WJ, Demarchi G. Vaginal discharge: an approach to diagnosis and management. Can Fam Physician. 1987 Aug;33:1847-52. PubMed PMID: 21263805 .

7. Jain KA. Ectopic vaginal insertion of an obstructed duplicated ureter in an adult female: demonstration by magnetic resonance imaging. Clin Imaging. 2007 Jan-Feb;31(1):54-6.

http://dx.doi.org/10.1016/i.clinimag.2006 .07.001 PubMed PMID: 17189850.

8. Chai TC, Davis R, Hawes LN, Twaddell WS. Ectopic ureter presenting as anterior wall vaginal prolapse. Female Pelvic Med Reconstr Surg. 2014 JulAug;20(4):237-9.

http://dx.doi.org/10.1097/SPV.00000000 00000082 PubMed PMID: 24978091.

9. Hanson GR, Gatti JM, Gittes GK, Murphy JP. Diagnosis of ectopic ureter as a cause of urinary incontinence. J Pediatr Urol. 2007 Feb;3(1):53-7. http://dx.doi.org/10.1016/i.jpurol.2005.06 .009 Epub 2006 Mar 30. PubMed PMID: 18947700. 